\title{
Determination of Polycyclic Aromatic Hydrocarbons in Cigarettes and Cigarette Smoke
}

\author{
Haruki Shimazu ${ }^{1}$ \\ ${ }^{1}$ School of Science and Engineering, Kindai University, Osaka, Japan \\ Correspondence: Haruki Shimazu, School of Science and Engineering, Kindai University, Osaka, 577 8502, Japan. \\ Tel: 81-6-4307-3559. E-mail: hshimazu@civileng.kindai.ac.jp
}

Received: July 7, 2016 Accepted: August 5, 2016 Online Published: September 29, 2016

doi:10.5539/ep.v5n2p15 URL: http://dx.doi.org/10.5539/ep.v5n2p15

\begin{abstract}
The present study examines the concentrations of polycyclic aromatic hydrocarbons (PAHs) in cigarettes and sidestream cigarette smoke. Nine PAHs were determined in sidestream cigarette smokes for five types of cigarettes. The volume of the experimental room is approximately $66 \mathrm{~m}^{3}$. The air samples in the room were collected before and after smoking. The total PAH concentrations were approximately $1.0 \mathrm{ng} / \mathrm{m}^{3}$ before smoking, but the median concentration and the range of PAHs were $29.1 \mathrm{ng} / \mathrm{m}^{3}$ and from 7.62 to $57.6 \mathrm{ng} / \mathrm{m}^{3}$ after smoking. The relationship between suspended particulate matter (SPM) and total PAHs after smoking is significant and proportional. This may indicate that the SPM formation is associated with PAH formation during smoking. Furthermore, nine PAHs were determined in the cigarettes. Median PAH contents in the five brands of cigarettes ranged from 221 to $936 \mathrm{ng}$ per cigarette before smoking and from 66.9 to $266 \mathrm{ng}$ per cigarette after smoking. Mean PAH emissions from cigarettes while smoking ranged from 257 to $1490 \mathrm{ng}$ per cigarette. The results show that PAHs in the cigarettes, and those generated during smoking, were emitted into the air.
\end{abstract}

Keywords: cigarette, polycyclic aromatic hydrocarbons, sidestream cigarette smoke, suspended particulate matter

\section{Introduction}

Exposure to cigarette smoke creates significant risks for developing cancers and a variety of respiratory and cardiovascular diseases (OEHHA 2005). Smoking has been recognized as a major cause of lung cancer (Lee et al. 2001; IARC 2004). Many studies have also provided evidence that smoking is a major cause of heart disease (Villablanca et al. 2000; Messner et al. 2014). Cigarette smoke has a complex chemical composition and contains numerous toxic chemicals and carcinogens, including polycyclic aromatic hydrocarbons (PAHs) (IARC 1987, 2010). PAHs have been measured in various environments because they are produced primarily as a result of incomplete combustion from anthropogenic sources such as cars, incinerators, and factories (Liu et al. 2015; Nam et al. 2008; Obrist et al. 2015; Subramanian et al. 2015). Benzo[a]pyrene is a PAH that has been classified as a Group 1 carcinogen (carcinogenic to humans) by the International Agency for Research on Cancer (IARC) (IARC 2016). Dibenz[a,h]anthracene, dibenz[a,j]acridine, dibenzo[a,l]pyrene have been classified as Group 2A carcinogens (probably carcinogenic to humans). Thirteen PAHs have been classified as Group 2B carcinogens (possibly carcinogenic to humans). Many PAHs, including benzo[a]pyrene and benzo[b]fluoranthene, are also considered to be mutagenic (Luch 2005). Because of their adverse effects some countries have regulated PAHs. For example, the United States Environmental Protection Agency has designated many PAHs in the Toxic Pollutant List and Priority Pollutant List under the Clean Water Act (USEPA 2016). Anthracene is included in the European Commission's REACH Candidate List (ECHA 2016).

Some experimental studies have reported PAHs in cigarette smoke (Ding et al. 2007; Lee et.al 2011; Vu et al. 2015). PAHs have been detected in some smokeless tobacco containing fire-cured tobacco varieties (Stepanov et al. 2010; McAdam et al. 2013). This is because when tobacco is fire-cured, PAHs formed by smoldering wood are absorbed in the tobacco leaves (Bentley et al. 1960). To understand PAH emissions from cigarettes and their formation during smoking, this study examined the occurrence of PAHs in cigarettes (leaves and filters) and sidestream cigarette smoke (particulate). 


\section{Materials and Methods}

\subsection{Samples}

Five brands of cigarettes were investigated in this study. The tar and nicotine contents per cigarette ranged from 1 to $21 \mathrm{mg}$ and from 0.1 to $1.9 \mathrm{mg}$, respectively. PAH in air samples and cigarette samples before and after smoking were measured as shown in Table 1.

The numbers of air samples collected for Brands A-D and Brand E before and after smoking were 5 and 4 , respectively. The air sampling room was $2.5 \mathrm{~m}$ high, $5.3 \mathrm{~m}$ in length, and $5.0 \mathrm{~m}$ in width (approximately $66 \mathrm{~m}^{3}$ ). The air samples were collected at a rate of $400 \mathrm{~L} / \mathrm{min}$ for $2.0 \mathrm{~h}\left(48 \mathrm{~m}^{3}\right)$ using a high-volume air sampler (HV-500R; Sibata Scientific Technology Ltd., Souka, Japan) before the cigarettes were smoked. A quartz fiber filter (QR-100; Advantec, Tokyo, Japan) was used in the sampler. The filter had a minimum particle collection efficiency of $99.99 \%$ for particles $0.3 \mu \mathrm{m}$ in diameter when air passed through the sampler at a speed of $5 \mathrm{~cm} / \mathrm{s}$. After the initial air sampling, two cigarettes were smoked in the experimental room. The sidestream smoke samples were collected at a rate of $400 \mathrm{~L} / \mathrm{min}$ for $2.75 \mathrm{~h}\left(66 \mathrm{~m}^{3}\right)$. Particulate PAHs collected on the quartz fiber filters were analyzed as discussed in the Analytical methods and instruments section.

PAHs in cigarettes before and after smoking were also analyzed. The numbers of cigarette samples (before smoking) and cigarette butt samples (after smoking) for Brands A-E were 4 and 1, respectively. The filter and leaf weights per cigarette are shown in Table 2. The arithmetic means of the weights of the five brands of cigarettes before smoking $(n=4)$ ranged from 0.19 to $0.25 \mathrm{~g}$ for the filters and from 0.54 to $0.72 \mathrm{~g}$ for the leaves. The weights in the five brands of cigarettes after smoking $(\mathrm{n}=1)$ ranged from 0.19 to $0.27 \mathrm{~g}$ for the filters and from 0.09 to $0.12 \mathrm{~g}$ for the leaves. Filters and leaves of the cigarettes were cut into three and six parts (Fig. 1), respectively. A portion of the filters and two portions of the leaves in the cigarette samples were analyzed as discussed in the Analytical methods and instruments section. After each of five brands of cigarettes were smoked, whole filters and leaves of the cigarette butt samples were also analyzed.

Table 1. Numbers of air and cigarette samples in this study

\begin{tabular}{lccccccc}
\hline & \multicolumn{2}{c}{ Air sample } & & \multicolumn{2}{c}{$\begin{array}{c}\text { Cigarette sample } \\
\text { (before smoking) }\end{array}$} & \multicolumn{2}{c}{$\begin{array}{c}\text { Cigarette butt sample } \\
\text { (after smoking) }\end{array}$} \\
\cline { 2 - 3 } \cline { 5 - 7 } & $\begin{array}{c}\text { Before } \\
\text { smoking }\end{array}$ & $\begin{array}{c}\text { After } \\
\text { smoking }\end{array}$ & & Filter & Leaf & Filter & Leaf \\
\hline Brand A & 5 & 5 & & 4 & $8(4 \times 2)$ & 1 & 1 \\
Brand B & 5 & 5 & & 4 & $8(4 \times 2)$ & 1 & 1 \\
Brand C & 5 & 5 & & 4 & $8(4 \times 2)$ & 1 & 1 \\
Brand D & 5 & 5 & & 4 & $8(4 \times 2)$ & 1 & 1 \\
Brand E & 4 & 4 & & 4 & $8(4 \times 2)$ & 1 & 1 \\
Total & 24 & 24 & & 20 & $40(20 \times 2)$ & 5 & 5 \\
\hline
\end{tabular}

Note. Two portions of cigarette leaves for cigarette sample were analyzed.

Table 2. Cigarette weights before and after smoking

\begin{tabular}{lcccc}
\hline & \multicolumn{2}{c}{$\begin{array}{c}\text { Cigarette sample } \\
\text { (before smoking) }\end{array}$} & \multicolumn{2}{c}{$\begin{array}{c}\text { Cigarette butt sample } \\
\text { (after smoking) }\end{array}$} \\
\cline { 2 - 5 } & Filter & Leaf & Filter & Leaf \\
\hline Brand A & 0.24 & 0.54 & 0.25 & 0.09 \\
Brand B & 0.25 & 0.58 & 0.25 & 0.11 \\
Brand C & 0.25 & 0.58 & 0.25 & 0.09 \\
Brand D & 0.24 & 0.67 & 0.27 & 0.12 \\
Brand E & 0.19 & 0.72 & 0.19 & 0.12 \\
\hline
\end{tabular}

Note. The weights for cigarette sample are the arithmetic means $(\mathrm{n}=4)$ and those for cigarette butt sample are the measured values $(\mathrm{n}=1)$. All units are $\mathrm{g}$. 


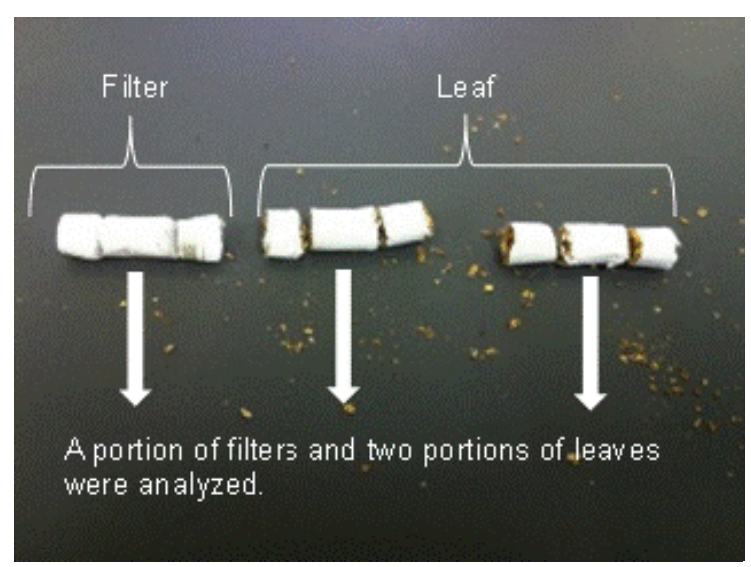

Figure 1. Analyzed portions of cigarette sample

\subsection{PAHS}

The nine PAHs shown in Table 3 were the target compounds in this study because many studies have reported that they are frequently detected in smoking environments. Some PAHs, for example BaA, BaP, BbF, BkF, DahA, FL and PY, are designated as hazardous substances that have the potential to harm humans through long-term exposure under Japanese air pollution control laws.

Nine standard material grade PAHs were purchased from Wako Pure Chemical Industries, Ltd. and were diluted with acetone and hexane to produce calibration standards.

\subsection{Analytical Methods and Instruments}

The quartz fiber filters were weighed using an electronic balance before and after smoking. The filters after smoking were cut into 16 portions. All portions were placed into $260 \mathrm{~mL}$ bottles and extracted with $40 \mathrm{~mL}$ of dichloromethane for $15 \mathrm{~min}$ by ultrasonic cleaner. The extract was concentrated to $2 \mathrm{~mL}$ using a rotary evaporator and was filtered using a disposable filter device (PURADISCTM 25TF; Whatman, Buckinghamshire, $\mathrm{UK})$. The extract was then concentrated to $0.1 \mathrm{~mL}$ under $\mathrm{N}_{2}$ flow. Finally, hexane was added to the extract to produce a final volume of $2 \mathrm{~mL}$.

Filters and leaves of the cigarettes before and after smoking were analyzed. Each sample was weighed, placed into a cellulose extraction thimble, and extracted with $40 \mathrm{~mL}$ of dichloromethane for $15 \mathrm{~min}$ by ultrasonic cleaner. The extract was concentrated to $2 \mathrm{~mL}$ using a rotary evaporator. The extract was filtered using a disposable filter device and concentrated to $0.1 \mathrm{~mL}$ under $\mathrm{N}_{2}$ flow. Hexane was then added to the extract to produce a final volume of $2 \mathrm{~mL}$.

Table 3. PAHs measured in this study

\begin{tabular}{lrcc}
\hline \multicolumn{1}{c}{ PAHs } & CAS No. & Abbreviation & Detection limits [pg] \\
\hline Anthracene & $120-12-7$ & AN & 4.0 \\
Benzo[ $a]$ anthracene & $56-55-3$ & BaA & 11.7 \\
Benzo[b]fluoranthene & $205-99-2$ & BbF & 9.2 \\
Benzo[k]fluoranthene & $207-08-9$ & BkF & 10.7 \\
Benzo[ghi]perylene & $191-24-2$ & BghiP & 22.6 \\
Benzo[ $a]$ pyrene & $50-32-8$ & BaP & 11.4 \\
Dibenz[a,h]anthracene & $53-70-3$ & DahA & 22.9 \\
Fluoranthene & $206-44-0$ & FL & 2.6 \\
Pyrene & $129-00-0$ & PY & 2.4 \\
\hline
\end{tabular}

Note. The abbreviations are used in this study. The detection limits were calculated as three times the signal-to-noise ratio at the baseline of the chromatogram. 
The PAH concentrations in the extracts were determined using gas chromatography-mass spectrometry (5975B inert XL E/CI MSD; Agilent Technologies, Santa Clara, CA, USA) equipped with a HP-5MS capillary column $(30 \mathrm{~m} \times 0.25 \mathrm{~mm}$ i.d., $0.25 \mu \mathrm{m}$ film thickness; Agilent Technologies). The GC conditions were as follows: splitless injection of $2 \mu \mathrm{L}$; injection port temperature of $250^{\circ} \mathrm{C}$; $\mathrm{GC}$ temperature program; $70{ }^{\circ} \mathrm{C}$ (hold $1.5 \mathrm{~min}$ ) to $180{ }^{\circ} \mathrm{C}$ at $20^{\circ} \mathrm{C} / \mathrm{min}$, and to $280^{\circ} \mathrm{C}$ at $5{ }^{\circ} \mathrm{C} / \mathrm{min}$ (hold $1 \mathrm{~min}$ ); and the carrier gas was helium. The mass spectrometer was operated in the electron impact mode with an electron energy of $70 \mathrm{eV}$. After each pollutant was identified using three representative fragment ions, it was quantified using the largest one. Quantification was performed using an external calibration method. The recoveries and the variation coefficients of the measured PAHs ranged from 75 to $110 \%$ and from 7 to $15 \%$, respectively.

Suspended particulate matter concentrations were calculated as the differences between the weights of the quartz fiber filters before and after air sampling divided by $48 \mathrm{~m}^{3}$ (before smoking) or $66 \mathrm{~m}^{3}$ (after smoking).

\section{Results and Discussion}

\subsection{PAHs in Air Samples}

Seven PAHs were detected in the air samples before smoking the cigarettes. Fluoranthene (FL) and pyrene (PY) were detected in almost all of the 24 samples. The median and maximum concentrations of FL were $0.46 \mathrm{ng} / \mathrm{m}^{3}$ and $1.30 \mathrm{ng} / \mathrm{m}^{3}$, respectively. The median and maximum concentrations for sum total of all PAHs were 1.06 $\mathrm{ng} / \mathrm{m}^{3}$ and $5.27 \mathrm{ng} / \mathrm{m}^{3}$.

Nine PAHs, as shown in Table 4, were detected in the air samples after smoking the cigarettes. Benzo[a]anthracene $(\mathrm{BaA})$, benzo[a]pyrene $(\mathrm{BaP})$, benzo[b]fluoranthene $(\mathrm{BbF})$, benzo[ghi]perylene (BghiP), FL and PY were detected in all 24 samples. The median concentration of BaP, which was the most abundant PAH, was $7.89 \mathrm{ng} / \mathrm{m}^{3}$ and its concentrations ranged from 2.50 to $14.6 \mathrm{ng} / \mathrm{m}^{3}$. Using BaP as an indicator of general PAH mixtures from emissions of coke ovens and similar combustion processes in urban air, and a reported value of $0.71 \% \mathrm{BaP}$ in the benzene-soluble fraction of coke oven emissions, the unit risk for $\mathrm{BaP}$ as an indicator air constituent for PAHs was estimated to be $8.7 \times 10^{-5} \mathrm{per} \mathrm{ng} / \mathrm{m}^{3}$ (WHO 1987). The lifetime respiratory cancer risk of the median concentration of BaP was approximately $6.9 \times 10^{-4}$. The median total PAH concentration was 29.1 $\mathrm{ng} / \mathrm{m}^{3}$ and the total PAH concentrations ranged from 7.62 to $57.6 \mathrm{ng} / \mathrm{m}^{3}$. The mean mole ratios for the PAHs were; $28.0 \%$ for $\mathrm{BaP}, 21.1 \%$ for $\mathrm{BaA}, 18.3 \%$ for $\mathrm{BbF}$ and BghiP, $4.6 \%$ for $\mathrm{FL}, 3.3 \%$ for dibenz[a,h]anthracene (DahA), 3.1 \% for anthracene (AN), $2.7 \%$ for PY, and $0.6 \%$ for benzo[k]fluoranthene $(\mathrm{BkF})$, respectively.

The correlation coefficients among the detected PAHs in air samples after smoking are summarized in Table 5. The correlation coefficients between AN and other PAHs were not significant because AN can play an important role as a precursor to higher PAHs (Kislov et al. 2013). However, the correlation coefficients for almost all of the other detected PAHs were greater than $0.643(\mathrm{p}<0.01)$, showing that each PAH was strongly related to the other PAHs. This is probably because the measured PAHs are formed through similar precursors (Richter et al. 1999, 2000, Vu et.al 2015).

The median concentration of suspended particulate matter (SPM) before smoking was $17 \mu \mathrm{g} / \mathrm{m}^{3}$ and the SPM concentrations ranged from 8 to $30 \mu \mathrm{g} / \mathrm{m}^{3}$. After smoking, the median SPM concentration was $117 \mu \mathrm{g} / \mathrm{m}^{3}$ and concentrations ranged from 96 to $146 \mu \mathrm{g} / \mathrm{m}^{3}$. The relationship between SPM concentrations and total PAH concentrations after smoking is presented in Fig. 2. The correlation coefficient was $0.559(\mathrm{p}<0.01)$. This may indicate that SPM formation is associated with PAH formation during smoking. 
Table 4. PAHs in air samples after smoking

\begin{tabular}{|c|c|c|c|c|c|}
\hline & Brand A & Brand B & Brand C & Brand D & Brand E \\
\hline \multirow{2}{*}{ AN } & $0.67(3 / 5)$ & $0.47(4 / 5)$ & $0.64(5 / 5)$ & $0.24(3 / 5)$ & N.D. (1/4) \\
\hline & [N.D. - 1.06] & [N.D. -1.41$]$ & {$[0.41-0.97]$} & [N.D. - 1.33] & [N.D. -0.41$]$ \\
\hline \multirow{2}{*}{$\mathrm{BaA}$} & $4.93(5 / 5)$ & $8.86(5 / 5)$ & $7.37(5 / 5)$ & $1.13(5 / 5)$ & $11.1(4 / 4)$ \\
\hline & {$[4.39-5.92]$} & {$[5.54-10.1]$} & {$[5.43-8.34]$} & {$[0.89-1.27]$} & {$[6.14-12.0]$} \\
\hline \multirow{2}{*}{$\mathrm{BbF}$} & $6.71(5 / 5)$ & $7.24(5 / 5)$ & $4.26(5 / 5)$ & $1.63(5 / 5)$ & $9.00(4 / 4)$ \\
\hline & {$[5.00-7.85]$} & {$[6.12-8.10]$} & {$[3.75-4.61]$} & {$[1.44-1.75]$} & {$[7.30-11.7]$} \\
\hline \multirow{2}{*}{$\mathrm{BkF}$} & N.D. $(1 / 5)$ & N.D. $(1 / 5)$ & N.D. $(0 / 5)$ & N.D. $(0 / 5)$ & N.D. (1/4) \\
\hline & [N.D. - 1.43] & [N.D. -1.82$]$ & [N.D.] & [N.D.] & [N.D. - 2.03] \\
\hline \multirow{2}{*}{ BghiP } & $7.47(5 / 5)$ & $9.02(5 / 5)$ & $3.88(5 / 5)$ & $1.80(5 / 5)$ & $12.0(4 / 4)$ \\
\hline & {$[4.40-9.28]$} & {$[7.64-9.80]$} & {$[3.05-4.19]$} & {$[1.14-1.94]$} & {$[10.2-12.9]$} \\
\hline \multirow{2}{*}{$\mathrm{BaP}$} & $7.88(5 / 5)$ & $11.5(5 / 5)$ & $7.44(5 / 5)$ & $2.97(5 / 5)$ & $12.8(4 / 4)$ \\
\hline & {$[7.22-9.10]$} & {$[9.19-12.4]$} & {$[5.93-8.38]$} & {$[2.50-3.20]$} & {$[10.1-14.6]$} \\
\hline \multirow{2}{*}{ DahA } & N.D. $(0 / 5)$ & $3.53(4 / 5)$ & $1.36(4 / 5)$ & $0.45(4 / 5)$ & N.D. (1/4) \\
\hline & [N.D.] & [N.D. -4.42$]$ & [N.D. -2.25$]$ & [N.D. -0.51$]$ & [N.D. - 4.11] \\
\hline \multirow{2}{*}{ FL } & $1.48(5 / 5)$ & $1.43(5 / 5)$ & $1.00(5 / 5)$ & $0.31(5 / 5)$ & $1.45(4 / 4)$ \\
\hline & {$[1.05-1.90]$} & {$[1.03-1.89]$} & {$[0.74-1.02]$} & {$[0.27-0.34]$} & {$[1.26-1.70]$} \\
\hline \multirow{2}{*}{ PY } & $0.96(5 / 5)$ & $0.83(5 / 5)$ & $0.54(5 / 5)$ & $0.18(5 / 5)$ & $0.86(4 / 4)$ \\
\hline & {$[0.64-1.25]$} & {$[0.64-1.34]$} & {$[0.43-0.64]$} & {$[0.12-0.20]$} & {$[0.37-1.06]$} \\
\hline \multirow{2}{*}{ ¿9PAHs } & $30.0(5 / 5)$ & $43.0(5 / 5)$ & $26.3(5 / 5)$ & $8.85(5 / 5)$ & $47.6(4 / 4)$ \\
\hline & {$[25.4-34.9]$} & {$[32.2-48.6]$} & {$[21.2-28.2]$} & {$[7.62-9.01]$} & {$[37.4-57.6]$} \\
\hline
\end{tabular}

Note. The upper values show median concentration (detection rate) and the lower values show [concentration range]. All units are $\mathrm{ng} / \mathrm{m}^{3}$. N.D. means Not detected. $\Sigma 9$ PAHs means total PAH concentrations.

Table 5. Pearson Coefficients for Correlations among the detected PAHs in air samples after smoking

\begin{tabular}{|c|c|c|c|c|c|c|c|c|}
\hline & AN & $\mathrm{BaA}$ & $\mathrm{BbF}$ & $\mathrm{BkF}$ & BghiP & $\mathrm{BaP}$ & DahA & FL \\
\hline $\mathrm{BaA}$ & -0.268 & & & & & & & \\
\hline $\mathrm{BbF}$ & -0.062 & $0.861^{*}$ & & & & & & \\
\hline $\mathrm{BkF}$ & - & 0.993 & 0.898 & & & & & \\
\hline BghiP & -0.153 & $0.804^{*}$ & $0.939^{*}$ & 0.991 & & & & \\
\hline $\mathrm{BaP}$ & -0.164 & $0.943^{*}$ & $0.952^{*}$ & 0.951 & $0.922^{*}$ & & & \\
\hline DahA & 0.021 & $0.888^{*}$ & $0.936^{*}$ & - & $0.960^{*}$ & $0.950^{*}$ & & \\
\hline FL & 0.123 & $0.723^{*}$ & $0.890^{*}$ & -0.975 & $0.774^{*}$ & $0.828^{*}$ & $0.935^{*}$ & \\
\hline PY & 0.074 & $0.643^{*}$ & $0.803^{*}$ & -0.869 & $0.710^{*}$ & $0.722 *$ & $0.905^{*}$ & $0.913^{*}$ \\
\hline
\end{tabular}




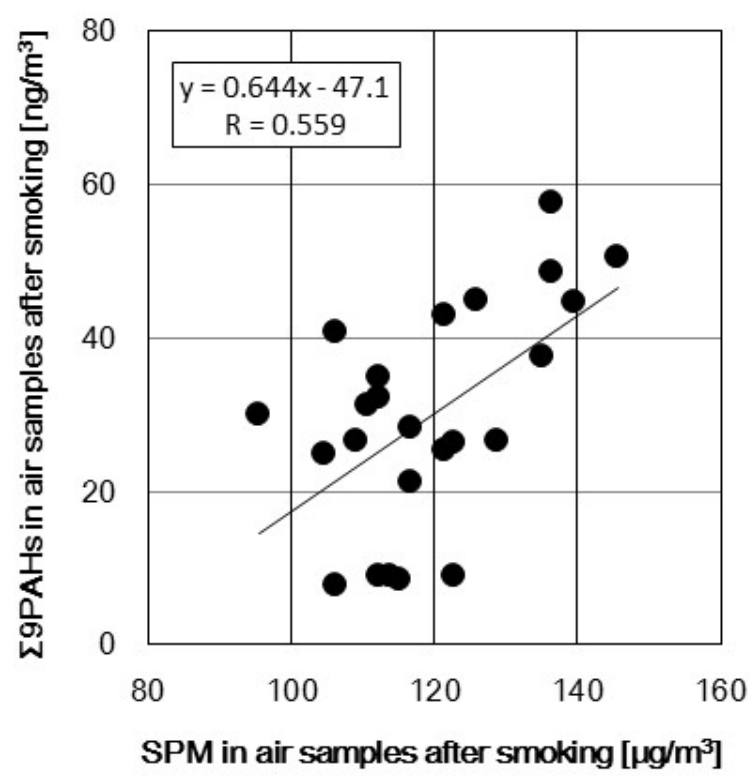

Figure 2. Relationship between SPM and total PAHs in air samples after smoking

\subsection{PAHs in Cigarettes}

PAHs in the cigarette filters before and after smoking are shown in Table 6 and Table 7, respectively. Five PAHs were detected in the cigarette filters before smoking. FL was detected in almost every samples. The median concentration of $\mathrm{BbF}$, which was the most abundant $\mathrm{PAH}$, was $87.9 \mathrm{ng} / \mathrm{g}$ and $\mathrm{BbF}$ concentrations ranged from N.D. to $139 \mathrm{ng} / \mathrm{g}$. The median total PAH concentration was $155 \mathrm{ng} / \mathrm{g}$ and total PAH concentrations ranged from N.D. to $460 \mathrm{ng} / \mathrm{g}$. Five PAHs were detected in the cigarette filters after smoking. The median total PAH concentration was $103 \mathrm{ng} / \mathrm{g}$ and concentrations ranged from N.D. to $355 \mathrm{ng} / \mathrm{g}$. The PAH concentrations in cigarette filters tended to be a little higher before smoking than after smoking. It may indicate that the PAHs produce during the cigarette production process and stay in the filters.

PAHs in the cigarette leaves before and after smoking are shown in Table 8 and Table 9, respectively. Nine PAHs were detected in the cigarette leaves before smoking. FL and PY were detected in all 40 samples. The median concentration of $\mathrm{BaA}$, the most abundant $\mathrm{PAH}$, was $257 \mathrm{ng} / \mathrm{g}$ and its concentrations ranged from N.D. to 441 $\mathrm{ng} / \mathrm{g}$. The median total PAH concentration was $750 \mathrm{ng} / \mathrm{g}$ and concentrations ranged from 206 to $2400 \mathrm{ng} / \mathrm{g}$. Six PAHs were detected in the cigarette leaves after smoking. AN, BaA, FL and PY were detected in all five samples. The median total PAH concentration was $1030 \mathrm{ng} / \mathrm{g}$ and total concentrations ranged from 744 to $1710 \mathrm{ng} / \mathrm{g}$. The PAH concentrations in cigarette leaves were greater after smoking than before smoking. The total concentrations of PAHs were higher in cigarette leaves than in cigarette filters. 
Table 6. PAHs in cigarette filters before smoking

\begin{tabular}{|c|c|c|c|c|c|}
\hline & Brand A & Brand B & Brand $\mathrm{C}$ & Brand D & Brand E \\
\hline \multirow{2}{*}{ AN } & $79.9(4 / 4)$ & N.D. (0/4) & N.D. $(0 / 4)$ & $23.7(2 / 4)$ & $76.7(3 / 4)$ \\
\hline & [31.9-324] & [N.D.] & [N.D.] & [N.D. - 195] & [N.D. - 118] \\
\hline \multirow{2}{*}{$\mathrm{BaA}$} & N.D. (0/4) & N.D. (0/4) & N.D. (0/4) & N.D. $(0 / 4)$ & N.D. (0/4) \\
\hline & [N.D.] & [N.D.] & [N.D.] & [N.D.] & [N.D.] \\
\hline \multirow{2}{*}{$\mathrm{BbF}$} & N.D. (1/4) & N.D. (1/4) & $83.6(4 / 4)$ & N.D. $(0 / 4)$ & N.D. (1/4) \\
\hline & [N.D. -139$]$ & [N.D. -68.9$]$ & {$[69.6-118]$} & [N.D.] & [N.D. - 117] \\
\hline \multirow{2}{*}{$\mathrm{BkF}$} & N.D. (0/4) & N.D. (0/4) & N.D. $(0 / 4)$ & N.D. (1/4) & N.D. $(0 / 4)$ \\
\hline & [N.D.] & [N.D.] & [N.D.] & [N.D. -26.5$]$ & [N.D.] \\
\hline \multirow{2}{*}{ BghiP } & N.D. $(0 / 4)$ & N.D. (0/4) & N.D. (0/4) & N.D. $(0 / 4)$ & N.D. (0/4) \\
\hline & [N.D.] & [N.D.] & [N.D.] & [N.D.] & [N.D.] \\
\hline \multirow{2}{*}{$\mathrm{BaP}$} & N.D. $(0 / 4)$ & N.D. $(0 / 4)$ & N.D. $(0 / 4)$ & N.D. $(0 / 4)$ & N.D. (0/4) \\
\hline & [N.D.] & [N.D.] & [N.D.] & [N.D.] & [N.D.] \\
\hline \multirow{2}{*}{ DahA } & N.D. (0/4) & N.D. (0/4) & N.D. (0/4) & N.D. (0/4) & N.D. (0/4) \\
\hline & [N.D.] & [N.D.] & [N.D.] & [N.D.] & [N.D.] \\
\hline \multirow{2}{*}{ FL } & $37.8(3 / 4)$ & $49.3(3 / 4)$ & $52.3(4 / 4)$ & $52.4(4 / 4)$ & $64.9(3 / 4)$ \\
\hline & [N.D. -84.1$]$ & [N.D. -71.0$]$ & {$[42.3-166]$} & {$[20.6-90.0]$} & [N.D. - 98.9] \\
\hline \multirow{2}{*}{ PY } & $19.6(2 / 4)$ & $30.6(3 / 4)$ & $40.9(4 / 4)$ & $38.0(3 / 4)$ & $29.2(2 / 4)$ \\
\hline & [N.D. -52.4$]$ & [N.D. -42.0$]$ & {$[25.2-110]$} & [N.D. - 56.1] & [N.D. -63.0$]$ \\
\hline \multirow{2}{*}{$\Sigma 9 \mathrm{PAHs}$} & $196(4 / 4)$ & $79.9(3 / 4)$ & $171(4 / 4)$ & $122(4 / 4)$ & $169(4 / 4)$ \\
\hline & {$[53.3-460]$} & [N.D. - 182] & {$[149-394]$} & {$[20.6-353]$} & {$[83.2-318]$} \\
\hline
\end{tabular}

Note. The upper values show median concentration (detection rate) and the lower values show [concentration range]. All units are ng/g. N.D. means Not detected. 29 PAHs means total PAH concentrations.

Table 7. PAHs in cigarette filters after smoking

\begin{tabular}{|c|c|c|c|c|c|}
\hline & Brand A & Brand B & Brand C & Brand D & Brand E \\
\hline AN & N.D. $(0 / 1)$ & N.D. $(0 / 1)$ & N.D. $(0 / 1)$ & N.D. $(0 / 1)$ & $101(1 / 1)$ \\
\hline $\mathrm{BaA}$ & N.D. $(0 / 1)$ & N.D. $(0 / 1)$ & N.D. $(0 / 1)$ & $42.4(1 / 1)$ & N.D. $(0 / 1)$ \\
\hline $\mathrm{BbF}$ & $56.6(1 / 1)$ & N.D. $(0 / 1)$ & N.D. $(0 / 1)$ & N.D. $(0 / 1)$ & N.D. $(0 / 1)$ \\
\hline $\mathrm{BkF}$ & N.D. $(0 / 1)$ & N.D. $(0 / 1)$ & N.D. $(0 / 1)$ & N.D. $(0 / 1)$ & N.D. $(0 / 1)$ \\
\hline BghiP & N.D. $(0 / 1)$ & N.D. $(0 / 1)$ & N.D. $(0 / 1)$ & N.D. $(0 / 1)$ & N.D. $(0 / 1)$ \\
\hline $\mathrm{BaP}$ & N.D. $(0 / 1)$ & N.D. $(0 / 1)$ & N.D. $(0 / 1)$ & N.D. $(0 / 1)$ & N.D. $(0 / 1)$ \\
\hline DahA & N.D. $(0 / 1)$ & N.D. $(0 / 1)$ & N.D. $(0 / 1)$ & N.D. $(0 / 1)$ & N.D. $(0 / 1)$ \\
\hline FL & $30.2(1 / 1)$ & N.D. $(0 / 1)$ & $9.6(1 / 1)$ & $26.7(1 / 1)$ & $135(1 / 1)$ \\
\hline PY & $26.2(1 / 1)$ & N.D. $(0 / 1)$ & N.D. $(0 / 1)$ & $22.9(1 / 1)$ & $119(1 / 1)$ \\
\hline$\Sigma 9 \mathrm{PAHs}$ & $113(1 / 1)$ & N.D. $(0 / 1)$ & $9.6(1 / 1)$ & $92.0(1 / 1)$ & $355(1 / 1)$ \\
\hline
\end{tabular}

Note. The values show median concentration (detection rate). All units are ng/g. N.D. means Not detected. ¿9PAHs means total PAH concentrations. 
Table 8. PAHs in cigarette leaves before smoking

\begin{tabular}{|c|c|c|c|c|c|}
\hline & Brand A & Brand B & Brand C & Brand D & Brand E \\
\hline \multirow{2}{*}{ AN } & $53.7(8 / 8)$ & N.D. $(0 / 8)$ & N.D. (2/8) & N.D. (3/8) & $69.9(6 / 8)$ \\
\hline & {$[39.4-502]$} & [N.D.] & [N.D. - 205] & [N.D. - 24.9] & [N.D. -86.4$]$ \\
\hline \multirow{2}{*}{$\mathrm{BaA}$} & N.D. (1/8) & N.D. $(0 / 8)$ & N.D. (2/8) & $169(7 / 8)$ & $341(6 / 8)$ \\
\hline & [N.D. - 239] & [N.D.] & [N.D. - 232] & [N.D. - 319] & [N.D. - 441] \\
\hline \multirow{2}{*}{$\mathrm{BbF}$} & $101(5 / 8)$ & N.D. (2/8) & $47.3(7 / 8)$ & N.D. $(3 / 8)$ & $97.8(7 / 8)$ \\
\hline & [N.D. - 356] & [N.D. -41.7$]$ & [N.D. -82.9$]$ & [N.D. - 199] & [N.D. - 119] \\
\hline \multirow{2}{*}{$\mathrm{BkF}$} & N.D. $(2 / 8)$ & N.D. $(0 / 8)$ & N.D. $(0 / 8)$ & $53.7(7 / 8)$ & N.D. $(0 / 8)$ \\
\hline & [N.D. - 376] & [N.D.] & [N.D.] & [N.D. - 195] & [N.D.] \\
\hline \multirow{2}{*}{ BghiP } & N.D. $(0 / 8)$ & N.D. $(0 / 8)$ & N.D. $(0 / 8)$ & N.D. (1/8) & N.D. $(0 / 8)$ \\
\hline & [N.D.] & [N.D.] & [N.D.] & [N.D. -75.5$]$ & [N.D.] \\
\hline \multirow{2}{*}{$\mathrm{BaP}$} & $58.9(4 / 8)$ & N.D. $(0 / 8)$ & N.D. $(3 / 8)$ & $68.4(6 / 8)$ & $89.0(6 / 8)$ \\
\hline & [N.D. - 424] & [N.D.] & [N.D. -82.2$]$ & [N.D. - 230] & [N.D. - 122] \\
\hline \multirow{2}{*}{ DahA } & N.D. $(2 / 8)$ & N.D. $(0 / 8)$ & N.D. $(0 / 8)$ & N.D. $(2 / 8)$ & N.D. $(0 / 8)$ \\
\hline & [N.D. - 483] & [N.D.] & [N.D.] & [N.D. - 174] & [N.D.] \\
\hline \multirow{2}{*}{ FL } & $304(8 / 8)$ & $195(8 / 8)$ & $221(8 / 8)$ & $162(8 / 8)$ & $387(8 / 8)$ \\
\hline & {$[276-402]$} & {$[119-263]$} & {$[145-354]$} & {$[113-210]$} & {$[304-547]$} \\
\hline \multirow{2}{*}{ PY } & $265(8 / 8)$ & $120(8 / 8)$ & $124(8 / 8)$ & $134(8 / 8)$ & $359(8 / 8)$ \\
\hline & {$[246-345]$} & [86.2 - 179] & [86.9-233] & {$[94.0-178]$} & {$[275-505]$} \\
\hline \multirow{2}{*}{ इ9PAHs } & $863(8 / 8)$ & $346(8 / 8)$ & $391(8 / 8)$ & $630(8 / 8)$ & $1260(8 / 8)$ \\
\hline & {$[608-2400]$} & {$[206-442]$} & {$[270-1090]$} & {$[238-1560]$} & {$[775-1570]$} \\
\hline
\end{tabular}

Note. The upper values show median concentration (detection rate) and the lower values show [concentration range]. All units are ng/g. N.D. means Not detected. 29 PAHs means total PAH concentrations.

Table 9. PAHs in cigarette leaves after smoking

\begin{tabular}{cccccc}
\hline & Brand A & Brand B & Brand C & Brand D & Brand E \\
\hline AN & $86.8(1 / 1)$ & $64.6(1 / 1)$ & $69.2(1 / 1)$ & $167(1 / 1)$ & $117(1 / 1)$ \\
BaA & $334(1 / 1)$ & $215(1 / 1)$ & $333(1 / 1)$ & $394(1 / 1)$ & $382(1 / 1)$ \\
BbF & N.D. (0/1) & N.D. (0/1) & N.D. (0/1) & $111(1 / 1)$ & $129(1 / 1)$ \\
BkF & N.D. (0/1) & N.D. (0/1) & N.D. (0/1) & N.D. (0/1) & N.D. (0/1) \\
BghiP & N.D. (0/1) & N.D. (0/1) & N.D. (0/1) & N.D. (0/1) & N.D. (0/1) \\
BaP & N.D. (0/1) & N.D. (0/1) & N.D. (0/1) & $154(1 / 1)$ & $164(1 / 1)$ \\
DahA & N.D. (0/1) & N.D. (0/1) & N.D. (0/1) & N.D. (0/1) & N.D. (0/1) \\
FL & $336(1 / 1)$ & $270(1 / 1)$ & $365(1 / 1)$ & $501(1 / 1)$ & $468(1 / 1)$ \\
PY & $253(1 / 1)$ & $195(1 / 1)$ & $264(1 / 1)$ & $386(1 / 1)$ & $398(1 / 1)$ \\
$\Sigma 9 P A H s$ & $1010(1 / 1)$ & $744(1 / 1)$ & $1030(1 / 1)$ & $1710(1 / 1)$ & $1660(1 / 1)$ \\
\hline
\end{tabular}

Note. The values show median concentration (detection rate). All units are ng/g. N.D. means Not detected. ¿9PAHs means total PAH concentrations.

\subsection{PAH Formation during Smoking}

The median contents for the nine PAHs in the five types of cigarettes before and after smoking are presented in Fig. 3. The median contents were calculated as the median concentrations for the nine PAHs in Tables 6-9 multiplied by the weights in Table 2. Median contents before smoking ranged from 20.0 to $47.0 \mathrm{ng}$ per cigarette 
for the filters and from 201 to $904 \mathrm{ng}$ per cigarette for the leaves. Those after smoking ranged from N.D. to 67.5 ng per cigarette for the filters and from 66.9 to $206 \mathrm{ng}$ per cigarette for the leaves. The PAH contents in the filters before and after smoking were approximately equal. However, those for the leaves were higher before smoking than after smoking. PAH emissions per cigarette were calculated as the difference between concentrations before and after smoking multiplied by $66 \mathrm{~m}^{3}$ and then divided by two because two cigarettes were smoked in the air sampling room (approximately $66 \mathrm{~m}^{3}$ ) during the experiments. The arithmetic means \pm standard errors (range) of the PAH emissions per cigarette were $899 \pm 62 \mathrm{ng}$ for Brand A, $1330 \pm 170 \mathrm{ng}$ for Brand $\mathrm{B}, 781 \pm 88 \mathrm{ng}$ for Brand C, $257 \pm 36 \mathrm{ng}$ for Brand D, and $1490 \pm 196 \mathrm{ng}$ for Brand E. Fourteen PAHs in mainstream smoke particulate matter from 28 brands of cigarettes in many counties have been reported (Ding et al. 2007). The mean emissions for seven high molecular PAHs (four to five rings) ranged from 84 to 284 ng per cigarette. The mean emissions in this study, for which high molecular PAHs dominated emissions, ranged from 257 to $1490 \mathrm{ng}$ per cigarette and, which was higher than the emissions reported by Ding et al. PAHs in sidestream smoke are likely to be more concerning than those in mainstream smoke. The results of this study show that cigarettes contain PAHs, especially in the cigarette leaves. It was also clear that PAHs in the cigarettes and PAHs generated during smoking are emitted into the air.

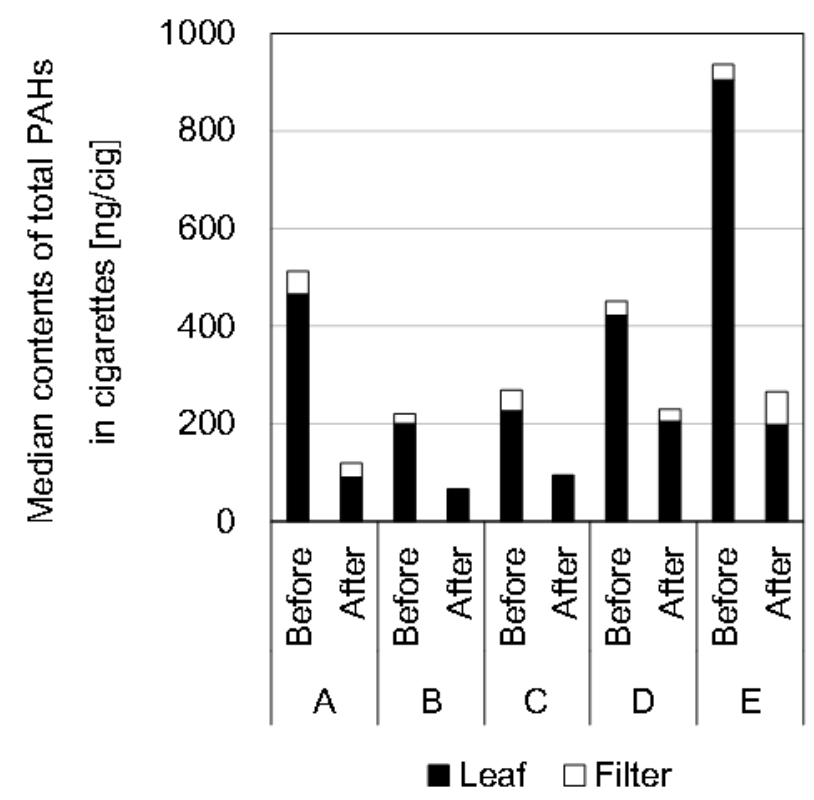

Figure 3. Comparison of median contents of total PAHs in cigarettes for Brands A-E

Note. Before indicates before smoking, and After indicates after smoking. Solid bars and open bars show contents for leaves and filters, respectively.

\section{Conclusion}

Nine PAHs in five types of cigarettes and the PAH emissions from cigarettes and their formation during smoking were investigated. PAHs were determined in air samples before and after two cigarettes were smoked in the air sampling room (approximately $66 \mathrm{~m}^{3}$ ). The total PAH concentrations were approximately $1.0 \mathrm{ng} / \mathrm{m}^{3}$ before smoking and ranged from 7.62 to $57.6 \mathrm{ng} / \mathrm{m}^{3}$ after smoking. Except for anthracene, the correlation coefficients between the detected PAHs in air samples after smoking were significantly positive. This is probably because the detected PAHs are formed from similar precursors. The correlation coefficient between SPM and the total concentration of the nine PAHs after smoking was also significantly positive. This may indicate that SPM formation is associated with PAH formation while smoking.

PAHs in the cigarettes before and after smoking were also measured. The total concentrations of the PAHs in the cigarette filters ranged from N.D. to $460 \mathrm{ng} / \mathrm{g}$ before smoking, and from N.D. to $355 \mathrm{ng} / \mathrm{g}$ after smoking. Those in the cigarette leaves ranged from 206 to $2400 \mathrm{ng} / \mathrm{g}$ before smoking, and from 744 to $1710 \mathrm{ng} / \mathrm{g}$ after smoking. Median PAH contents in the five brands of cigarettes before smoking ranged from 20.0 to $47.0 \mathrm{ng}$ per cigarette for the filters and from 201 to $904 \mathrm{ng}$ per cigarette for the leaves. Those after smoking ranged from N.D. to 67.5 
ng per cigarette for the filters and from 66.9 to $206 \mathrm{ng}$ per cigarette for the leaves. Mean PAH emissions from the cigarettes to the air while smoking ranged from 257 to $1490 \mathrm{ng}$ per cigarette. The results show that PAHs in the cigarettes, and those generated during smoking, were emitted into the air.

\section{Acknowledgments}

The author would like to thank Kindai University for providing the grant to complete this research. The author acknowledge the assistance given by Hajime Kaku and Takahiro Fujiwara.

\section{References}

Bentley, H. R., \& Burgan, J. G. (1960) Polynuclear hydrocarbons in tobacco and tobacco smoke Part 1 3:4-Benzopyrene. Analyst, 85, 723-727. http://dx.doi.org/10.1039/an9608500723

Ding, Y. S., Ashley, D. L., \& Watson, C. H. (2007) Determination of 10 carcinogenic polycyclic aromatic hydrocarbons in mainstream cigarette smoke. Journal of Agricultural and Food Chemistry, 55, 5966-5973. Retrieved from http://pubs.acs.org/doi/pdf/10.1021/jf070649o

ECHA. (2016). The Candidate List. Retrieved from $\mathrm{http} / / /$ echa.europa.eu/regulations/reach/authorisation/the-candidate-list

IARC. (1987). Overall evaluations of carcinogenicity: an updating of IARC monographys, Vols. 1-42, Suppl. 7. IARC Monographs on the Evaluation of Carcinogenic Risks to Humans. Lyon, France: IARC, WHO.

IARC. (2004). Tobacco smoke and involuntary smoking, Vol. 83 IARC monographys on the evaluation of the carcinogenic risk of chemicals to human. Lyon, France: IARC, WHO.

IARC. (2010). Some non-heterocyclic polycyclic aromatic hydrocarbons and some related exposures, Vol. 92. IARC Monographs on the Evaluation of Carcinogenic Risks to Humans. Lyon, France: IARC, WHO.

IARC. (2016). Some Industrial Chemicals, Vol. 115. IARC Monographs on the Evaluation of Carcinogenic Risks to Humans. Lyon, France: IARC, WHO.

Kislov, V. V., Sadovnikov, A. I., \& Mebel, A. M. (2013) Formation mechanism of polycyclic aromatic hydrocarbons beyond the second aromatic ring. The Journal of Physical Chemistry A, 117, 4794-4816. Retrieved from http://pubs.acs.org/doi/ipdf/10.1021/jp402481y

Lee, C. H., Ko, Y. C., Cheng, L. S., Lin, Y. C., Lin, H. J., Huang, M. S., Huang, J. J., Kao, E. L., \& Wang, H. Z. (2001) The heterogeneity in risk factors of lung cancer and the difference of histologic distribution between genders in Taiwan. Cancer Causes and Control, 12(4), 289-300. Retrieved from http://download.springer.com/static/pdf/144/art\%253A10.1023\%252FA\%253A1011270521900.pdf?origin $\mathrm{Url}=\mathrm{http} \% 3 \mathrm{~A} \% 2 \mathrm{~F} \% 2 \mathrm{Flink}$.springer.com\%2Farticle $\% 2 \mathrm{~F} 10.1023 \% 2 \mathrm{FA} \% 3 \mathrm{~A} 1011270521900 \&$ token $2=\mathrm{exp}=$ 1467937968 acl=\%2Fstatic\%2Fpdf\%2F144\%2Fart\%25253A10.1023\%25252FA\%25253A1011270521900 .pdf\%3ForiginUrl\%3Dhttp\%253A\%252F\%252Flink.springer.com\%252Farticle\%252F10.1023\%252FA\%2 53A1011270521900* hmac $=$ edc4e928d8972c17795fb2a08ce36609aac552972223701 f061fe256ad8a5381

Lee, H. L., Hsieh, D. P. H., \& Li, L. A. (2011) Polycyclic aromatic hydrocarbons in cigarette sidestream smoke particulates from a Taiwanese brand and their carcinogenic relevance. Chemosphere, 82, 477-482. Retrieved from http://www.sciencedirect.com/science/article/pii/S004565351001060X

Liu, Y., Gao, Y., Yu, N., Zhang, C., Wang, S., Ma, L., Zhao, J., \& Lohmann, R. (2015) Particulate matter, gaseous and particulate polycyclic aromatic hydrocarbons (PAHs) in an urban traffic tunnel of China: Emission from on-road vehicles and gas-particle partitioning. Chemosphere, 134, 52-59. Retrieved from http://www.sciencedirect.com/science/article/pii/S004565351500288X

Luch, A. (2005). The Carcinogenic Effects of Polycyclic Aromatic Hydrocarbons. London: Imperial College Press. http://dx.doi.org/10.1142/p306

McAdam, K. G., Faizi, A., Kimpton, H., Porter, A., \& Rodu, B. (2013) Polycyclic aromatic hydrocarbons in US and Swedish smokeless tobacco products. Chemistry Central Journal, 7, 151. Retrieved from http://download.springer.com/static/pdf/335/art\%253A10.1186\%252F1752-153X-7-151.pdf?originUrl=http $\% 3 \mathrm{~A} \% 2 \mathrm{~F} \% 2 \mathrm{Fccj}$.springeropen.com\%2Farticle\%2F10.1186\%2F1752-153X-7-151\&token2=exp=14679374 $04 \sim \mathrm{acl}=\% 2 \mathrm{Fstatic} \% 2 \mathrm{Fpdf} \% 2 \mathrm{~F} 33 \% 2 \mathrm{Fart} \% 25253 \mathrm{~A} 10.1186 \% 25252 \mathrm{~F} 1752-153 \mathrm{X}-7-151 . \mathrm{pdf} * \mathrm{hmac}=\mathrm{c} 31 \mathrm{cb}$ 756da26b28631f5547cfb759c5f907a056dd35c854cf52495eb545182c6

Messner, B., \& Bernhard, D. (2014) Smoking and cardiovascular disease: mechanisms of endothelial dysfunction and early atherogenesis. Arteriosclerosis Thrombosis, and Vascular Biology, 34(3), 509-515. Retrieved from http://atvb.ahajournals.org/content/34/3/509.full.pdf + html 
Nam, J. I., Thomas, G. O., Jaward, F. M., Steinnes, E., Gustafsson, O., \& Jones, K. C. (2008). PAHs in background soils from Western Europe: Influence of atmospheric deposition and soil organic matter. Chemosphere, 70, 1596-1602. $\quad$ Retrieved from http://www.sciencedirect.com/science/article/pii/S0045653507009873

Obrist, D., Zielinska, B., \& Perlinger, J. A. (2015). Accumulation of polycyclic aromatic hydrocarbons (PAHs) and oxygenated PAHs (OPAHs) in organic and mineral soil horizons from four U.S. remote forests. Chemosphere, 134, 98-105. Retrieved from http://www.sciencedirect.com/science/article/pii/S0045653515003318

OEHHA. (2005). Proposed identification of environmental tobacco smoke as a toxic air contaminant, part B: Health effects assessment for environmental tobacco smoke. CA, USA: California EPA Sacramento.

Richter, H., \& Howard, J. B. (2000). Formation of polycyclic aromatic hydrocarbons and their growth to soot - a review of chemical reaction pathways. Progress in Energy and Combustion Science, 26, 565-608. Retrieved from http://www.sciencedirect.com/science/article/pii/S0360128500000095

Richter, H., Grieco, W. J., \& Howard, J. B. (1999). Formation mechanism of polycyclic aromatic hydrocarbons and fullerenes in premixed benzene flames. Combustion and Flame, 119, 1-22. Retrieved from http://ac.els-cdn.com/S0010218099000322/1-s2.0-S0010218099000322-main.pdf?_tid=66b2839e-44a2-11e 6-95dc-00000aacb35e\&acdnat=1467937678_3c3c455f108c0062a6909a84833b6fa 0

Stepanov, I., Villalta, P. W., Knezevich, A., Jensen, J., Hatsukami, D., \& Hecht, S. S. (2010). Analysis of 23 polycyclic aromatic hydrocarbons in smokeless tobacco by gas chromatography-mass spectrometry. Chemical Research in Toxicology, 23, 66-73. Retrieved from http://pubs.acs.org/doi/ipdf/10.1021/tx900281u

Subramanian, A., Kunisue, T., \& Tanabe, S. (2015). Recent status of organohalogens, heavy metals and PAHs pollution in specific locations in India. Chemosphere, 137, 122-134. Retrieved from http://www.sciencedirect.com/science/article/pii/S0045653515006840

USEPA. (2016). Toxic and Priority Pollutants Under the Clean Water Act. Retrieved from https://www.epa.gov/eg/toxic-and-priority-pollutants-under-clean-water-act\#toxic

Villablanca, A. C., McDonald, J. M., \& Rutledge, J. C. (2000) Smoking and cardiovascular disease. Clinics In Chest Medicine, 21(1), 159-172. Retrieved from http://www.sciencedirect.com/science/article/pii/S0272523105700150

Vu, A. T., Taylor, K. M., Holman, M. R., Ding, Y. S., Hearn, B., \& Watson, C. H. (2015) Polycyclic aromatic hydrocarbons in the mainstream smoke of popular U.S. cigarettes. Chemical Research in Toxicology, 28, 1616-1626. Retrieved from http://pubs.acs.org/doi/ipdf/10.1021/acs.chemrestox.5b00190

WHO. (1987). Polynuclear aromatic hydrocarbons (PAH). In: Air quality guidelines for Europe (pp. 105-117). Copenhagen: WHO Regional Office for Europe.

\section{Copyrights}

Copyright for this article is retained by the author(s), with first publication rights granted to the journal.

This is an open-access article distributed under the terms and conditions of the Creative Commons Attribution license (http://creativecommons.org/licenses/by/4.0/). 